\title{
宜昌圈椅埫 $\mathbf{A}$ 型花岗岩锆石 U-Pb 年龄和 $\mathbf{H f}$ 同位素与 扬子大陆古元古代克拉通化作用
}

熊庆, 郑建平 ${ }^{*}$, 余淳梅, 苏玉平, 汤华云, 张志海

中国地质大学地球科学学院, 地质过程与矿产资源国家重点实验室, 武汉 430074

* 联系人, E-mail: jpzheng@cug.edu.cn

2008-07-08 收稿, 2008-08-19 接受

国家自然科学基金(批准号: 90714002, 40425002 和 40772042)和国家重点基础研究发展计划(批准号: 2006CB403502)资助项目

摘要 对侵位于湖北宜昌崆岭杂岩中的圈椅埫花岗岩进行了主量元素、微量元素、锆 石 $\mathrm{U}-\mathrm{Pb}$ 年龄和 $\mathrm{Hf}$ 同位素分析. 结果表明, 圈椅埫花岗岩富硅、碱, 贫钲、镁, 富集 $\mathrm{Ga}$, $\mathrm{Y}, \mathrm{Zr}$ 和 $\mathrm{Nb}$, 弓损 $\mathrm{Sr}$ 和 $\mathrm{Ba}$, 表现出后造山 $\mathrm{A}$ 型花岗岩 $\left(\mathrm{A}_{2}\right.$ 型)的特征. 圈椅䏴 $\mathrm{A}$ 型花岗 岩的锆石 $90 \%$ 是谐和的, 并给出平均 $1854 \mathrm{Ma}$ 的古元古代岩体结晶年龄. 古元古代锆石 初始 $\left({ }^{176} \mathrm{Hf} /{ }^{177} \mathrm{Hf}\right)_{\mathrm{i}}$ 比值为 $0.280863 \sim 0.281134, \varepsilon_{\mathrm{Hf}}(t)$ 均为负值(最低为-26.3), 亏损地幔模 式年龄是 2.9 3.3 Ga (平均 $3.0 \mathrm{Ga}$ ), 平均地壳模式年龄高达 3.6 4.2 Ga (平均 $3.8 \mathrm{Ga}$ ). 表 面年龄为中太古代 $(2859 \mathrm{Ma})$ 的锆石有略高的亏损地幔模式年龄 $(3.4 \mathrm{Ga})$ 但相似的平均 地壳模式年龄 $(3.8 \mathrm{Ga})$. 这些数据表明形成圈椅埫 $\mathrm{A}$ 型花岗岩的初始物质非常古老, 至 少老于 $2.9 \mathrm{Ga}$, 甚至可以追溯到冥太古代. 与圈椅埫 $\mathrm{A}$ 型花岗岩形成有关的古元古代地 壳熔融事件记录着扬子大陆克拉通化过程, 可能与 Columbia 超大陆聚合后-裂解前的伸 展作用所引起的深部太古宙地壳拉张垮塌有关.
关键词

后造山 A 型花岗岩

锆石

$\mathrm{U}-\mathrm{Pb}$ 年龄

$\mathrm{Hf}$ 同位素

古元古代大陆克拉通化

扬子大陆
扬子和华北大陆, 是中国东部两个最大的有前 寒武结晶基底的克拉通块体. 在华北, $3.4 \sim 3.8 \mathrm{Ga}$ 古 老地壳岩石相继在河北曹庄 ${ }^{[1,2]}$ 、辽宁鞍山 ${ }^{[3,4]}$ 、河南 信阳 ${ }^{[5]}$ 等地被发现. 在扬子, 除少量太古宙岩石(如崆 岭杂岩 $)^{[6,7]}$ 出露外, 大量出露的岩石主要是元古宙的 [8]. 最近, Zhang等人 ${ }^{[9]}$ 在崆岭杂岩附近的莲沱组碎屑 沉积岩中发现了 $3.8 \mathrm{Ga}$ 的锆石. 通过对湖北京山、湖 南宁乡和贵州镇远 3 个地区煌斑岩中捕虏晶锆石的 研究, Zheng等人 ${ }^{[10]}$ 发现在扬子实际上存在广泛未暴 露的太古宙基底, 只不过这样的基底经历了后期的 强烈增生或改造作用. 随着近些年对 $\mathrm{A}$ 型花岗岩研究 的深入, 将其最初仅限于碱性、无水、非造山的定义 ${ }^{[11]}$ 扩展到非造山的和后造山的两种类型 ${ }^{[12,13]}$. 我们 对侵位于湖北宜昌崆岭杂岩中的圈椅埫花岗岩 (图 1), 进行岩石主量元素和微量元素分析, 发现其为后 造山的 $\mathrm{A}$ 型花岗岩. 利用热离子源发射质谱计, 袁海
华等人 ${ }^{[14]}$ 对圈椅埫花岗岩中的锆石进行分层蒸发测 试获得形成年龄是 $1.85 \mathrm{Ga}$. 本文在详细的锆石形貌 和内部结构特征研究基础上, 对该花岗岩中锆石进行 了原位的 $\mathrm{U}-\mathrm{Pb}$ 年龄和 $\mathrm{Hf}$ 同位素配套分析. 发现圈椅埫 $\mathrm{A}$ 型花岗岩的初始物质来源非常古老 $(\geq 2.9 \mathrm{Ga})$, 其形 成过程可能与Columbia超大陆裂解之前的后造山伸展 环境中所发生的深部地壳拉张垮塌有关, 记录着扬子 大陆的古元古代 $(\sim 1.85 \mathrm{Ga})$ 克拉通化作用.

\section{1 地质背景及岩体简介}

崆岭杂岩出露于宜昌西北约 $100 \mathrm{~km}$ 的黄陵䄰归 至兴山一带, 呈一穴隆状产出, 面积约 $360 \mathrm{~km}^{2}$ (图 1), 是扬子乃至华南出露面积最大的太古宙杂岩. 该杂 岩主要有 3 类岩石组合构成: (1) 英云闪长-奥长花岗花岗质(TTG)片麻岩, 其中以奥长花岗质和英云闪长 质片麻岩占主体; (2) 上覆于 TTG 片麻岩的变沉积 


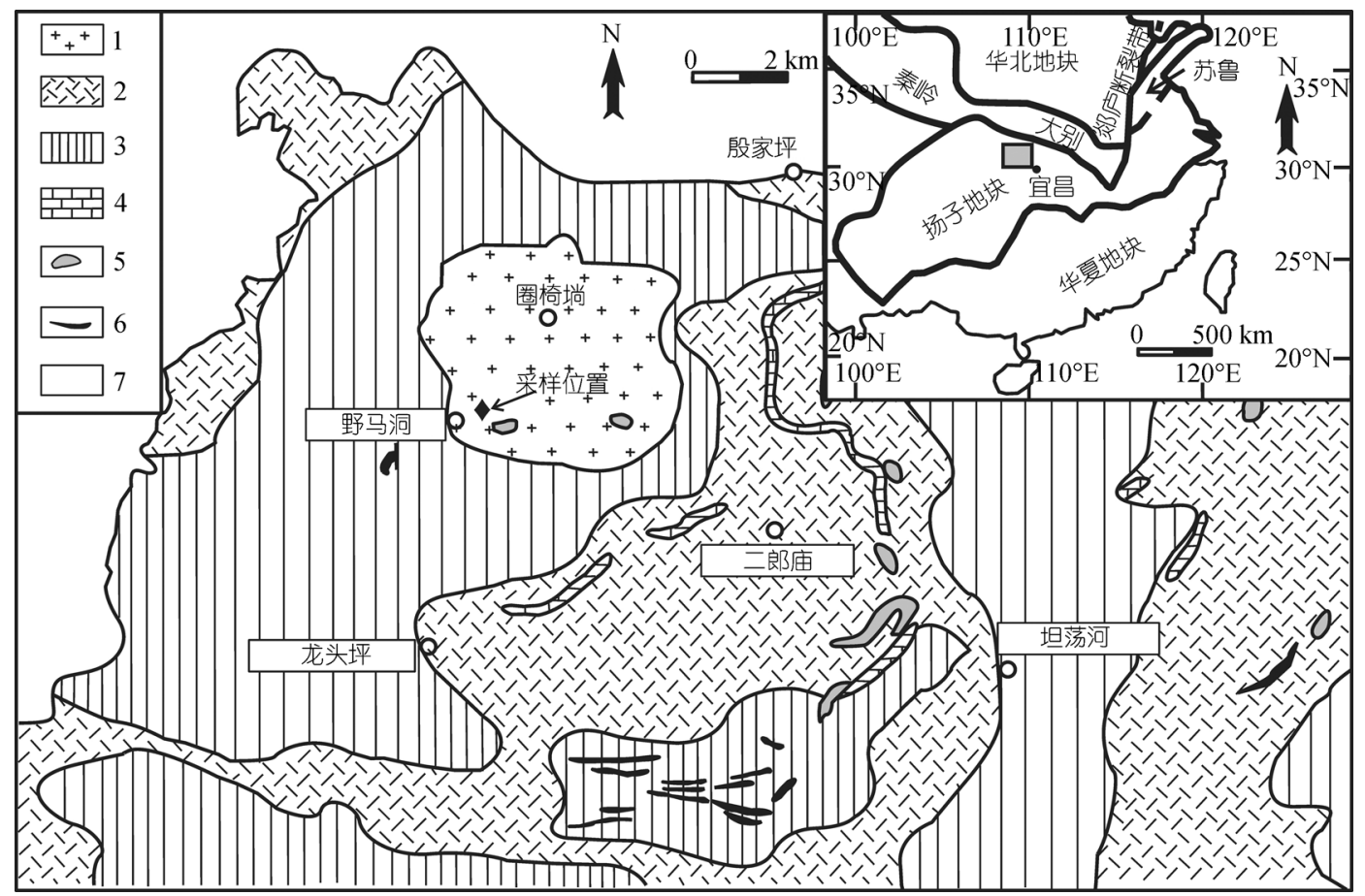

图 1 圈椅埫花岗岩岩体及崆岭杂岩地质简图(修改自文献 $[6,10]$ )

1, 圈椅埫花岗岩; 2 , 变沉积岩; 3 , 英云闪长质-奥长花岗质-花岗质片麻岩(TTG 片麻岩); 4 , 大理岩层; 5 , 超镂铁质侵入体; 6 , 镁铁质岩 墙; 7, 元古宙及显生宙沉积盖层

岩; (3) 以透镜状、香肠状或似层状局部产于片麻岩 中的角闪岩和麻粒岩等. 三类岩石组合的比例大致 是 $0.51: 0.44: 0.05^{[6]}$. 崆岭杂岩的北部和南部分别有圈 椅埫花岗岩 $(\sim 1.85 \mathrm{Ga})^{[14]}$ 和黄陵花岗岩 $(\sim 820 \mathrm{Ma})^{[15]}$ 侵入.

圈椅埫花岗岩岩体平面上呈近等轴状岩株产出, 出露面积约 $21 \mathrm{~km}^{2}$, 主要由似斑状碱长花岗岩构成. 样品(Ymd7)取自该岩体西南部的野马洞(图 1), 主要 由条纹微斜长石 $(60 \%$ 75\%)、石英 $(20 \%$ 25\%)、酸性 斜长石 $(5 \% \sim 15 \%)$ 和黑云母 $(1 \% \sim 2 \%)$ 等组成, 其中部 分条纹微斜长石呈斑晶产出(粒径 5 10 mm), 基质由 条纹微斜长石、酸性斜长石和石英等组成, 它们的粒 度多在 $2 \sim 3 \mathrm{~mm}$.

\section{2 分析方法}

用于全岩主量元素和微量元素分析的样品, 无 污染粉碎至 200 目以下. 样品主量元素和微量元素分 析都在中国地质大学(武汉)地质过程与矿产资源国 家重点实验室完成. 样品主量元素组成用湿化学法 测试获得. 样品微量元素组成用 ICP-MS 方法测试获 得, 其分析的准确度优于 $10 \%$, 详细的过程见文
献[16].

除锆石阴极发光图像分析在中国地质大学 (武 汉) 地质过程与矿产资源国家重点实验室完成外，其 余的锆石测试分析, 均在澳大利亚Macquarie大学 GEMOC中心完成. 锆石 U-Pb 同位素原位分析在 Agilent HP4500 电感耦合等离子质谱与定制的 266 $\mathrm{nm}$ UV激光剥蚀探针的联机上进行的. 激光束直径 20 30 $\mu \mathrm{m}$, 激光剥蚀样品的深度为 $30 \sim 50 \mu \mathrm{m}$, 激光 脉冲速率 $10 \mathrm{~Hz}$, 激光束脉冲能量 $1 \mathrm{~mJ}$. 详细的测试 技术说明见www.es.mq.edu.au/GEMOC/AnMethods. 普 通铅校正采用Andersen ${ }^{[17]}$ 所描述的方法进行排除, 实际上对研究样品的作用不大. 锆石LA-ICPMS测年 的精度和误差见文献 $[18,19]$.

锆石 $\mathrm{Hf}$ 同位素是在 $\mathrm{Nu}$ plasma多接受器的电感耦 合等离子质谱与Merchantek EO LUV $213 \mathrm{~nm}$ 激光剥 蚀探针的联机上进行. 分析时激光束直径 $40 \sim 50 \mu \mathrm{m}$, 激光剥蚀样品深度为 $40 \sim 60 \mu \mathrm{m}$, 激光剥蚀时间 $80 \sim 120$ s. 测定时用GEMOC标样GJ-1 作外标. 激光 脉冲速率 $10 \mathrm{~Hz}$, 激光束的脉冲能量为 $0.6 \sim 1.3 \mathrm{~mJ}$. LA-MC-ICPMS Hf同位素测试的运行条件、详细的分 析过程及数据精度等见文献[20]. $\varepsilon_{\mathrm{Hf}}$ 值计算过程中采 
用文献[21]所推荐的球粒陨石值. $T_{\mathrm{DM}}$ (亏损地幔模式 年龄)和 $T_{\text {crust }}$ (平均地壳模式年龄)值计算过程中采用 Scherer等人 ${ }^{[22]}$ 建议的Lu-Hf衰变常数 $1.865 \times 10^{-11} \mathrm{a}^{-1}$, 并使用大陆平均地壳的 ${ }^{176} \mathrm{Lu} /{ }^{177} \mathrm{Hf}=0.015^{[20,23]}$ 来计算 $T_{\text {crust. }}$.

\section{3 分析结果}

\section{1 主量元素和微量元素}

圈椅埫花岗岩(样品 Ymd7, 06HL01 和 06HL02) 的主量元素和微量元素组成见表 1. 主量元素具有富 硅 $\left(\mathrm{SiO}_{2}=72.6 \mathrm{wt} \% \sim 74.5 \mathrm{wt} \%\right)$ 、富碱 $\left(\mathrm{Na}_{2} \mathrm{O}+\mathrm{K}_{2} \mathrm{O}=\right.$ $8.67 \mathrm{wt} \% \sim 9.12 \mathrm{wt} \%)$ 、富铁 $\left(\mathrm{FeO}^{*} /\left(\mathrm{FeO}^{*}+\mathrm{MgO}\right)=\right.$
$0.89 \sim 0.93)$ 、贫钲 $(\mathrm{CaO}=0.68 \mathrm{wt} \% \sim 1.25 \mathrm{wt} \%)$ 、贫 镁 $(\mathrm{MgO}=0.16 \mathrm{wt} \% \sim 0.33 \mathrm{wt} \%)$ 、贫铝 $\left(\mathrm{Al}_{2} \mathrm{O}_{3}=12.4\right.$ $\mathrm{wt} \% \sim 12.8 \mathrm{wt} \%)$ 的特征, 与A型花岗岩的主量元素特征 相似(图 2(a), (b)). 微量元素具Ga (21.0 22.8 ppm)、Y (42.8 52.5 ppm)、 Zr (230 408 ppm)、 Nb (24.3 25.9 $\mathrm{ppm})(\mathrm{ppm}=1 \mu \mathrm{g} / \mathrm{g}$, 下同)含量高的特点; 10000 $\mathrm{Ga} / \mathrm{Al}$ 介于 $3.09 \sim 3.46$ 之间 (平均 3.29), 略低于

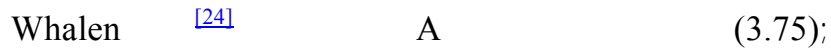
Sr (32.8 116 ppm)、Ba (198 797 ppm) 表现出相对 LREE亏损(没有提供图件). 微量元素也表现出 $\mathrm{A}$ 型花 岗岩的特点(图 2(c), (d)).

表 1 湖北宜昌圈椅埫花岗岩主量元素 $(w t \%)$ 和微量元素 $(p p m)$ 分析结果 ${ }^{a)}$

\begin{tabular}{|c|c|c|c|c|c|}
\hline 样品号 & Ymd7-1 & Ymd7-2(重复样) & 06HL01 & 06HL02-1 & 06HL02-2(重复样) \\
\hline $\mathrm{SiO}_{2}$ & 74.5 & 74.3 & 72.8 & 72.6 & \\
\hline $\mathrm{TiO}_{2}$ & 0.18 & 0.18 & 0.38 & 0.40 & \\
\hline $\mathrm{Al}_{2} \mathrm{O}_{3}$ & 12.4 & 12.5 & 12.6 & 12.8 & \\
\hline $\mathrm{Fe}_{2} \mathrm{O}_{3}$ & 0.37 & 0.41 & 0.76 & 1.10 & \\
\hline $\mathrm{FeO}$ & 1.74 & 1.72 & 2.15 & 1.48 & \\
\hline $\mathrm{MnO}$ & 0.03 & 0.03 & 0.04 & 0.04 & \\
\hline $\mathrm{MgO}$ & 0.16 & 0.17 & 0.33 & 0.32 & \\
\hline $\mathrm{CaO}$ & 0.68 & 0.73 & 1.25 & 1.23 & \\
\hline $\mathrm{Na}_{2} \mathrm{O}$ & 3.32 & 3.28 & 3.42 & 3.32 & \\
\hline $\mathrm{K}_{2} \mathrm{O}$ & 5.80 & 5.81 & 5.25 & 5.51 & \\
\hline $\mathrm{P}_{2} \mathrm{O}_{5}$ & 0.02 & 0.02 & 0.07 & 0.07 & \\
\hline $\mathrm{H}_{2} \mathrm{O}^{-}$ & 0.12 & 0.10 & 0.08 & 0.12 & \\
\hline 烧失量 & 0.66 & 0.64 & 0.64 & 0.84 & \\
\hline 总量 & 100.0 & 99.9 & 99.8 & 99.9 & \\
\hline $\mathrm{Be}$ & 4.35 & 4.51 & 4.54 & 3.75 & 3.86 \\
\hline $\mathrm{Sc}$ & 2.66 & 2.53 & 4.79 & 5.25 & 5.25 \\
\hline $\mathrm{V}$ & 3.02 & 2.78 & 15.7 & 15.3 & 15.5 \\
\hline $\mathrm{Cr}$ & 6.64 & 6.56 & 6.32 & 2.93 & 2.89 \\
\hline $\mathrm{Ni}$ & 4.07 & 3.98 & 3.75 & 1.70 & 1.64 \\
\hline $\mathrm{Cu}$ & 5.28 & 5.26 & 5.81 & 2.55 & 3.27 \\
\hline $\mathrm{Zn}$ & 21.1 & 21.1 & 39.7 & 35.9 & 36.6 \\
\hline $\mathrm{Ga}$ & 22.4 & 22.8 & 21.4 & 21.0 & 21.0 \\
\hline $\mathrm{Rb}$ & 374 & 375 & 260 & 237 & 230 \\
\hline $\mathrm{Sr}$ & 32.8 & 33.1 & 116 & 115 & 114 \\
\hline $\mathrm{Y}$ & 52.5 & 52.1 & 42.8 & 45.6 & 46.8 \\
\hline $\mathrm{Zr}$ & 233 & 230 & 349 & 408 & 377 \\
\hline $\mathrm{Nb}$ & 25.9 & 25.8 & 24.4 & 24.3 & 25.3 \\
\hline Cs & 1.91 & 1.92 & 1.90 & 1.43 & 1.43 \\
\hline $\mathrm{Ba}$ & 201 & 198 & 659 & 774 & 797 \\
\hline $\mathrm{La}$ & 132 & 142 & 97.5 & 116 & 114 \\
\hline $\mathrm{Ce}$ & 248 & 267 & 188 & 218 & 216 \\
\hline $\operatorname{Pr}$ & 26.4 & 28.3 & 20.9 & 25.2 & 24.8 \\
\hline $\mathrm{Nd}$ & 77.6 & 82.9 & 66.8 & 79.9 & 80.7 \\
\hline $\mathrm{Sm}$ & 11.8 & 12.5 & 11.3 & 12.7 & 13.2 \\
\hline $\mathrm{Eu}$ & 0.45 & 0.47 & 1.17 & 1.33 & 1.34 \\
\hline
\end{tabular}


表 1(续)

\begin{tabular}{|c|c|c|c|c|c|}
\hline 样品号 & Ymd7-1 & Ymd7-2(重复样) & 06HL01 & 06HL02-1 & 06HL02-2(重复样) \\
\hline $\mathrm{Gd}$ & 9.25 & 9.70 & 8.83 & 10.0 & 10.2 \\
\hline $\mathrm{Tb}$ & 1.36 & 1.39 & 1.30 & 1.38 & 1.41 \\
\hline Dy & 8.06 & 8.19 & 7.75 & 7.96 & 8.12 \\
\hline Ho & 1.67 & 1.70 & 1.55 & 1.60 & 1.67 \\
\hline Er & 5.02 & 5.03 & 4.37 & 4.48 & 4.71 \\
\hline $\mathrm{Tm}$ & 0.81 & 0.80 & 0.68 & 0.70 & 0.72 \\
\hline $\mathrm{Yb}$ & 5.33 & 5.41 & 4.43 & 4.58 & 4.75 \\
\hline $\mathrm{Lu}$ & 0.74 & 0.76 & 0.61 & 0.63 & 0.64 \\
\hline $\mathrm{Hf}$ & 8.17 & 7.86 & 9.53 & 11.0 & 10.2 \\
\hline $\mathrm{Ta}$ & 1.86 & 1.87 & 1.57 & 1.63 & 1.70 \\
\hline $\mathrm{Pb}$ & 48.3 & 48.6 & 23.6 & 26.2 & 26.4 \\
\hline Th & 54.7 & 54.3 & 27.9 & 36.8 & 34.7 \\
\hline $\mathrm{U}$ & 3.18 & 3.16 & 3.06 & 2.41 & 2.43 \\
\hline
\end{tabular}

a) $w \mathrm{t} \%$ 表示质量分数, 下同
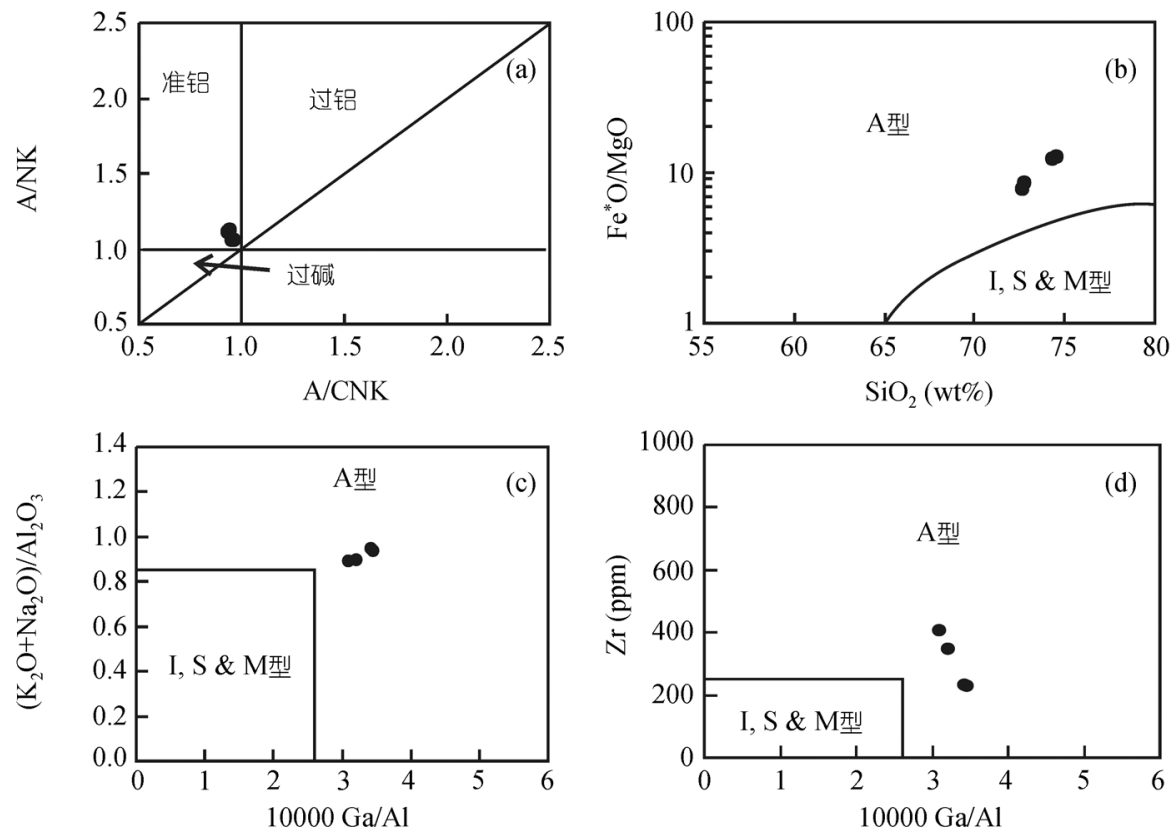

图 2 圈椅埫花岗岩主量元素和微量元素判别图

(a) A/NK-A/CNK图解, 圈椅埫花岗岩投点于准铝区域; (b) $\mathrm{FeO} / \mathrm{MgO}-\mathrm{SiO}_{2}$ 图解, 显示富铁和富硅的特征, 落于 $\mathrm{A}$ 型花岗岩区域; (c)和(d)分 别为 $\left(\mathrm{Na}_{2} \mathrm{O}+\mathrm{K}_{2} \mathrm{O}\right) / \mathrm{Al}_{2} \mathrm{O}_{3}-10000 \mathrm{Ga} / \mathrm{Al}$ 图解和 $\mathrm{Zr}-10000 \mathrm{Ga} / \mathrm{Al}$ 图解，投点在A型花岗岩区域，底图来自Whalen等人 ${ }^{[24]}$

\section{2 锆石 $\mathrm{U}-\mathrm{Pb}$ 年龄}

进行锆石 $\mathrm{U}-\mathrm{Pb}$ 年代学测定的是样品 Ymd7. 所 分选锆石颜色较单一, 主体淡黄色, 少量浅褐色. 形 态多自形(图 3), 部分破裂残缺状. 大小在 $50 \mu \mathrm{m} \times 60$ $\mu \mathrm{m} \sim 100 \mu \mathrm{m} \times 300 \mu \mathrm{m}$ 之间, 长宽比多在 $2.0 \sim 3.0$ 之 间. 个别颗粒外形受到溶蚀作用影响(如 Ymd7-20, Ymd7-31). 多数颗粒有典型岩浆锆石的振荡环带.

锆石的 Th 和 $U$ 含量达几十到几百个 $\mathrm{ppm}$, 除
Ymd7-29 为 0.79 外, 其余颗粒的 $\mathrm{Th} / \mathrm{U}$ 比值均在 $1.25 \sim$ 1.93 之间(表 2), 具典型岩浆锆石的 $\mathrm{Th} / \mathrm{U}$ 比值特征. 除 Ymd7-25, Ymd7-29 和 Ymd7-30 三个颗粒是不谐和 的, 并分别给出 $(1829 \pm 10),(2859 \pm 8)$ 和 $(3388 \pm 14) \mathrm{Ma}$ 的 ${ }^{207} \mathrm{~Pb} /{ }^{206} \mathrm{~Pb}$ 表面年龄外, 其余 12 个颗粒基本上是

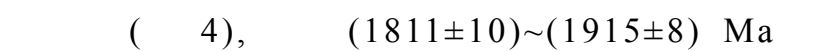
${ }^{207} \mathrm{~Pb} /{ }^{206} \mathrm{~Pb}$ 表面年龄, 它们的加权平均值为 $(1854 \pm 17)$ Ma (95\% Conf., MSWD = 8.6, $N=12)$ ，构成的不一致 
表 2 湖北宜昌圈椅埫 A 型花岗岩锆石激光 ICP-MS 年龄结果 ${ }^{\text {a) }}$

\begin{tabular}{|c|c|c|c|c|c|c|c|c|c|c|c|c|c|c|c|c|c|c|c|c|}
\hline \multirow{2}{*}{ 颗粒 } & \multicolumn{8}{|c|}{ 校正后同位素比值 } & \multirow{2}{*}{$\begin{array}{l}\mathrm{Th}^{* /} \\
\mathrm{ppm}\end{array}$} & \multirow{2}{*}{$\begin{array}{l}\mathrm{U}^{*} / \\
\mathrm{ppm}\end{array}$} & \multirow[b]{2}{*}{$\mathrm{Th} / \mathrm{U}$} & \multicolumn{8}{|c|}{ 校正后表面年龄/Ma } & \multirow{2}{*}{$\begin{array}{c}\text { 普通 } \mathrm{Pb} \\
\text { 含量 } \\
(\%)\end{array}$} \\
\hline & $\begin{array}{l}{ }^{207} \mathrm{~Pb} / \\
{ }^{206} \mathrm{~Pb}\end{array}$ & $1 \sigma$ & $\begin{array}{l}{ }^{207} \mathrm{~Pb} / \\
{ }^{235} \mathrm{U}\end{array}$ & $1 \sigma$ & $\begin{array}{l}{ }^{206} \mathrm{~Pb} / \\
{ }^{238} \mathrm{U}\end{array}$ & $1 \sigma$ & $\begin{array}{l}{ }^{208} \mathrm{~Pb} / \\
{ }^{232} \mathrm{Th}\end{array}$ & $1 \sigma$ & & & & $\begin{array}{l}{ }^{207} \mathrm{~Pb} / \\
{ }^{206} \mathrm{~Pb} \\
\end{array}$ & $1 \sigma$ & $\begin{array}{c}{ }^{207} \mathrm{~Pb} / \\
{ }^{23} \mathrm{U}\end{array}$ & $1 \sigma$ & $\begin{array}{c}{ }^{206} \mathrm{~Pb} / \\
{ }^{238} \mathrm{U}\end{array}$ & $1 \sigma$ & $\begin{array}{l}{ }^{208} \mathrm{~Pb} / \\
{ }^{232} \mathrm{Th} \\
\end{array}$ & $1 \sigma$ & \\
\hline Ymd7-17 & 0.11403 & 0.00116 & 5.16691 & 0.05629 & 0.32867 & 0.00357 & 0.09587 & 0.00096 & 535 & 281 & 1.91 & 1865 & 8 & 1847 & 9 & 1832 & 17 & 1850 & 18 & 0 \\
\hline Ymd7-18 & 0.11324 & 0.00115 & 4.58381 & 0.04786 & 0.29361 & 0.00305 & 0.08580 & 0.00084 & 568 & 455 & 1.25 & 1852 & 9 & 1746 & 9 & 1660 & 15 & 1664 & 16 & 0 \\
\hline Ymd7-19 & 0.11344 & 0.00126 & 4.96918 & 0.06087 & 0.31774 & 0.00372 & 0.09172 & 0.00102 & 105 & 76 & 1.38 & 1855 & 9 & 1814 & 10 & 1779 & 18 & 1774 & 19 & 0 \\
\hline Ymd7-20 & 0.11267 & 0.00114 & 4.82353 & 0.04978 & 0.31050 & 0.00320 & 0.08910 & 0.00085 & 810 & 475 & 1.70 & 1843 & 9 & 1789 & 9 & 1743 & 16 & 1725 & 16 & 0 \\
\hline Ymd7-21 & 0.11326 & 0.00133 & 5.02464 & 0.06605 & 0.32178 & 0.00394 & 0.09290 & 0.00112 & 179 & 122 & 1.47 & 1852 & 10 & 1823 & 11 & 1798 & 19 & 1796 & 21 & 0 \\
\hline Ymd7-22 & 0.11390 & 0.00121 & 4.99026 & 0.05645 & 0.31778 & 0.00349 & 0.09364 & 0.00096 & 144 & 75 & 1.91 & 1863 & 8 & 1818 & 10 & 1779 & 17 & 1809 & 18 & 0 \\
\hline Ymd7-23 & 0.11325 & 0.00167 & 4.99899 & 0.07669 & 0.32019 & 0.00401 & 0.09154 & 0.00122 & 34 & 20 & 1.75 & 1852 & 12 & 1819 & 13 & 1791 & 20 & 1770 & 23 & 0 \\
\hline Ymd7-24 & 0.11728 & 0.00121 & 4.31052 & 0.04501 & 0.26657 & 0.00275 & 0.08101 & 0.00079 & 743 & 418 & 1.78 & 1915 & 8 & 1695 & 9 & 1523 & 14 & 1574 & 15 & 0 \\
\hline Ymd7-25 & 0.11178 & 0.00119 & 1.88948 & 0.02388 & 0.12261 & 0.00152 & 0.03534 & 0.00040 & 1650 & 1260 & 1.31 & 1829 & 10 & 1077 & 8 & 746 & 9 & 702 & 8 & 0 \\
\hline Ymd7-26 & 0.11072 & 0.00125 & 4.95642 & 0.06435 & 0.32471 & 0.00402 & 0.09127 & 0.00105 & 280 & 145 & 1.93 & 1811 & 10 & 1812 & 11 & 1813 & 20 & 1765 & 19 & 0 \\
\hline Ymd7-27 & 0.11235 & 0.00120 & 5.11872 & 0.05525 & 0.33046 & 0.00344 & 0.09732 & 0.00100 & 96 & 56 & 1.74 & 1838 & 9 & 1839 & 9 & 1841 & 17 & 1877 & 18 & 0 \\
\hline Ymd7-28 & 0.11143 & 0.00123 & 5.05901 & 0.06509 & 0.32930 & 0.00414 & 0.09617 & 0.00128 & 967 & 758 & 1.28 & 1823 & 10 & 1829 & 11 & 1835 & 20 & 1850 & 24 & 0 \\
\hline Ymd7-29 & 0.20408 & 0.00211 & 8.01929 & 0.09437 & 0.28509 & 0.00335 & 0.04686 & 0.00058 & 816 & 1039 & 0.79 & 2859 & 8 & 2233 & 11 & 1617 & 17 & 926 & 11 & 0 \\
\hline Ymd7-30 & 0.28461 & 0.00601 & 15.60797 & 0.30384 & 0.39767 & 0.00680 & 0.24707 & 0.00515 & 61 & 35 & 1.71 & 3388 & 14 & 2853 & 19 & 2158 & 31 & 4463 & 83 & 0 \\
\hline Ymd7-31 & 0.11281 & 0.00130 & 4.99363 & 0.06533 & 0.32127 & 0.00397 & 0.09074 & 0.00118 & 1063 & 620 & 1.72 & 1845 & 10 & 1818 & 11 & 1796 & 19 & 1756 & 22 & 0 \\
\hline
\end{tabular}



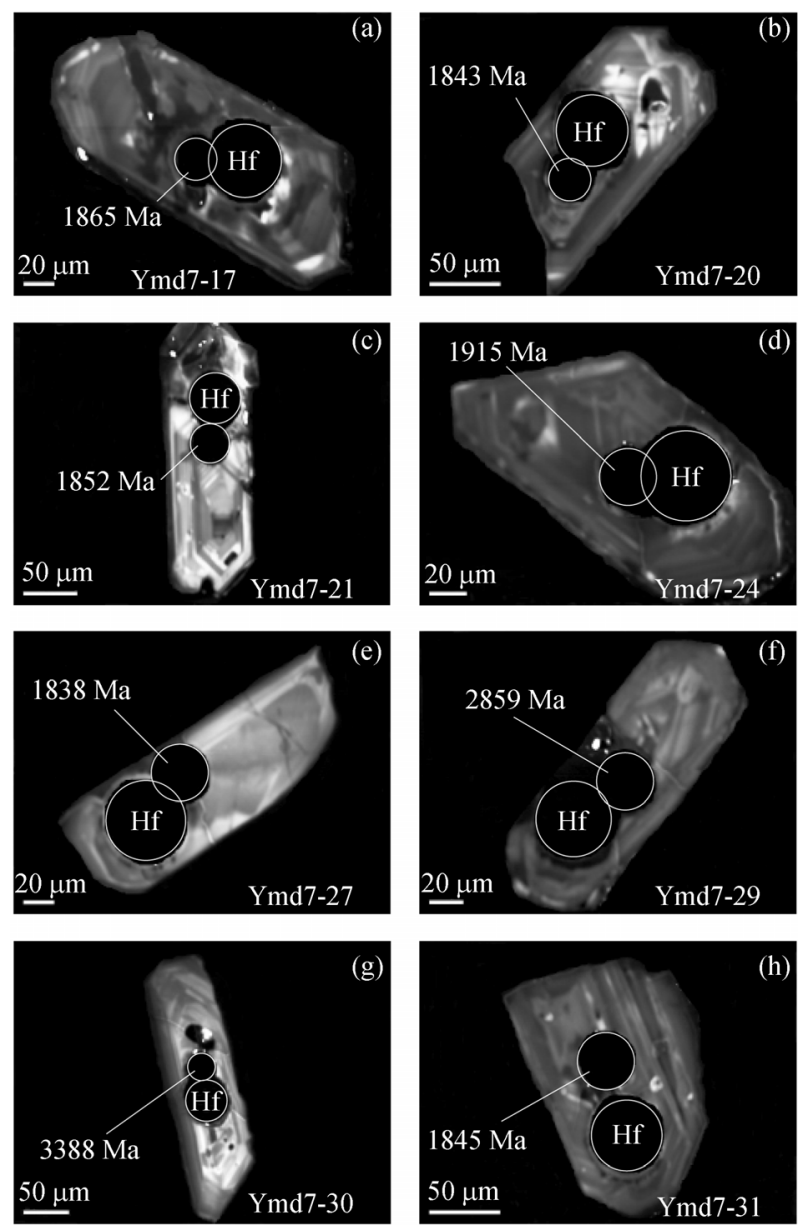

图 3 样品 Ymd7 代表性锆石阴极发光图像及激光分析点位 白色小圈为 $\mathrm{U}-\mathrm{Pb}$ 年龄分析位置; 白色大圈为 $\mathrm{Hf}$ 同位素分析位置; $\mathrm{Hf}: \mathrm{Hf}$ 同位素; 年龄为 ${ }^{207} \mathrm{~Pb} /{ }^{206} \mathrm{~Pb}$ 表面年龄

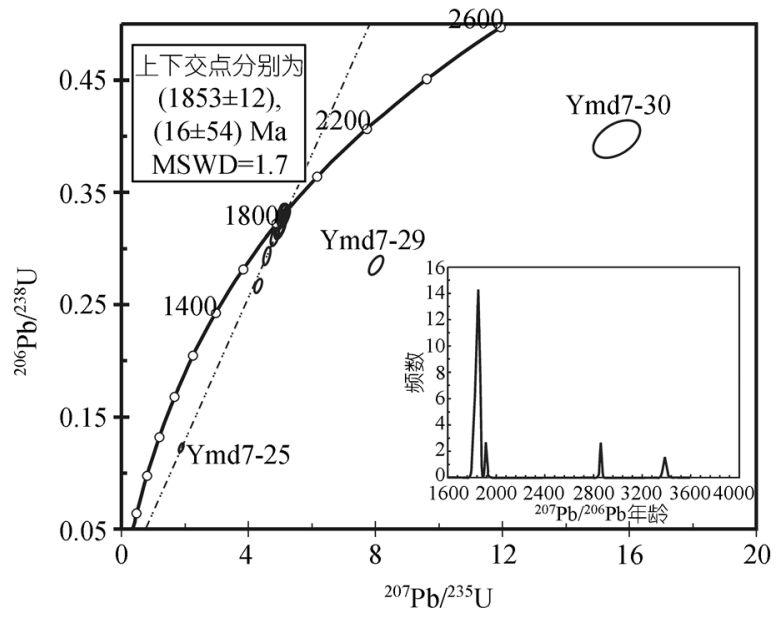

图 4 样品 Ymd7 锆石 U-Pb 年龄谐和图

线上交点为 $(1853 \pm 12) \mathrm{Ma}(\mathrm{MSWD}=1.7)$.

\section{3 锆石 Hf 同位素}

对上述 15 颗 U-Pb 定年的锆石, 我们又进行了 $\mathrm{Hf}$ 同位素测定(表 3). 除 Ymd7-29 的初始 $\left({ }^{176} \mathrm{Hf} /{ }^{177} \mathrm{Hf}\right)_{\mathrm{i}}$ 比 值为 0.280749 外, 其余颗粒 (不含 Ymd7-30)的结果在 $(0.281044 \pm 0.000024)$. 古元古代锆石均有负的 $\varepsilon_{\mathrm{Hf}}(t)$ $(-26.3 \sim-16.7)$, 并给出 $2.9 \sim 3.3 \mathrm{Ga}$ 的 $T_{\mathrm{DM}}$ 和 $3.6 \sim$ $4.2 \mathrm{Ga}$ 的 $T_{\text {crust }}$; Ymd7-29 的中太古代继承核具有-7.3 的 $\varepsilon_{\mathrm{Hf}}(t)$, 并给出 $3.4 \mathrm{Ga}$ 的 $T_{\mathrm{DM}}$ 和 $3.8 \mathrm{Ga}$ 的 $T_{\text {crust }}$.

\section{4 讨论}

\section{1 太古宙古老地壳物质的古元古代重熔作用}

（i ）扬子崆岭太古宙地壳物质的存在. 圈椅埫 花岗岩锆石给出古老的太古宙年龄信息，如有的颗粒

表 3 湖北宜昌圈椅埫 A 型花岗岩锆石代表性主元素(wt\%)和 Lu-Hf 同位素分析结果 ${ }^{\text {a) }}$

\begin{tabular}{|c|c|c|c|c|c|c|c|c|c|c|c|c|}
\hline 颗粒 & $\begin{array}{c}\mathrm{HfO}_{2} * / \\
\mathrm{wt} \% \\
\end{array}$ & $\begin{array}{c}\mathrm{Y}_{2} \mathrm{O}_{3} * / \\
\text { wt } \%\end{array}$ & ${ }^{176} \mathrm{Hf} /{ }^{177} \mathrm{Hf}$ & $1 \sigma$ & ${ }^{176} \mathrm{Lu} /{ }^{177} \mathrm{Hf}$ & ${ }^{176} \mathrm{Yb} /{ }^{177} \mathrm{Hf}$ & 年龄/Ma & $\left({ }^{176} \mathrm{Hf} /{ }^{177} \mathrm{Hf}\right)_{\mathrm{i}}$ & $\varepsilon_{\mathrm{Hf}}(t)$ & $1 \sigma$ & $T_{\mathrm{DM}} / \mathrm{Ga}$ & $T_{\text {crust }} / \mathrm{Ga}$ \\
\hline Ymd7-17 & 1.36 & 0.11 & 0.281093 & 0.000016 & 0.001480 & 0.039173 & 1854 & 0.281041 & -20.0 & 0.6 & 3.0 & 3.8 \\
\hline Ymd7-18 & 1.47 & 0.18 & 0.281112 & 0.000028 & 0.001469 & 0.039150 & 1854 & 0.281060 & -19.3 & 1.0 & 3.0 & 3.7 \\
\hline Ymd7-19 & 1.25 & 0.05 & 0.281157 & 0.000027 & 0.000654 & 0.017416 & 1854 & 0.281134 & -16.7 & 0.9 & 2.9 & 3.6 \\
\hline Ymd7-20 & 1.22 & 0.61 & 0.281075 & 0.000020 & 0.001395 & 0.040655 & 1854 & 0.281026 & -20.5 & 0.7 & 3.1 & 3.8 \\
\hline Ymd7-21 & 1.56 & 0.05 & 0.281106 & 0.000023 & 0.000655 & 0.017844 & 1854 & 0.281083 & -18.5 & 0.8 & 3.0 & 3.7 \\
\hline Ymd7-22 & 1.43 & 0.11 & 0.281103 & 0.000014 & 0.000467 & 0.013376 & 1854 & 0.281087 & -18.4 & 0.5 & 3.0 & 3.7 \\
\hline Ymd7-23 & 1.16 & 0.08 & 0.281073 & 0.000019 & 0.000577 & 0.016355 & 1854 & 0.281053 & -19.6 & 0.7 & 3.0 & 3.8 \\
\hline Ymd7-24 & 1.42 & 0.20 & 0.281078 & 0.000018 & 0.001569 & 0.044025 & 1854 & 0.281023 & -20.6 & 0.6 & 3.1 & 3.8 \\
\hline Ymd7-25 & 1.61 & 0.37 & 0.281105 & 0.000016 & 0.002261 & 0.064074 & 1854 & 0.281025 & -20.5 & 0.6 & 3.1 & 3.8 \\
\hline Ymd7-26 & 1.46 & 0.09 & 0.281060 & 0.000033 & 0.000945 & 0.025675 & 1854 & 0.281027 & -20.5 & 1.2 & 3.0 & 3.8 \\
\hline Ymd7-27 & 1.29 & 0.16 & 0.281056 & 0.000017 & 0.000507 & 0.014811 & 1854 & 0.281038 & -20.1 & 0.6 & 3.0 & 3.8 \\
\hline Ymd7-28 & 1.62 & 0.27 & 0.280919 & 0.000045 & 0.001584 & 0.042343 & 1854 & 0.280863 & -26.3 & 1.6 & 3.3 & 4.2 \\
\hline Ymd7-29 & 1.30 & 0.05 & 0.280791 & 0.000017 & 0.000771 & 0.018409 & 2859 & 0.280749 & -7.3 & 0.6 & 3.4 & 3.8 \\
\hline Ymd7-30 & 1.35 & 0.12 & 0.281097 & 0.000020 & 0.001055 & 0.028937 & & & & & 3.0 & \\
\hline Ymd7-31 & 1.47 & 0.22 & 0.281024 & 0.000018 & 0.000655 & 0.018280 & 1854 & 0.281001 & -21.4 & 0.6 & 3.1 & 3.9 \\
\hline
\end{tabular}

a) *代表电子探针结果; 年龄为锆石谐和年龄的加权平均值 $1854 \mathrm{Ma}\left(\right.$ 除 $\mathrm{Ymd} 7-29$ 为 ${ }^{207} \mathrm{~Pb} /{ }^{206} \mathrm{~Pb}$ 表面年龄); $\left({ }^{176} \mathrm{Hf} /{ }^{177} \mathrm{Hf}\right)_{\mathrm{i}}$, 对应于锆石结晶 年龄的初始 $\mathrm{Hf}$ 同位素组成; Ymd7-30 因 U-Pb 年龄极不谐和, 没有计算与年龄有关的参数 
给出不谐和的太古宙 ${ }^{207} \mathrm{~Pb} /{ }^{206} \mathrm{~Pb}$ 表面年龄 (如 $\mathrm{Ymd} 7-29,2859 \mathrm{Ma}$ ), 以及 $2.9 \sim 3.4 \mathrm{Ga}$ 的 $T_{\mathrm{DM}}$ (平均 $3.1 \mathrm{Ga}$ )和 $3.6 \sim 4.2 \mathrm{Ga}$ 的 $T_{\text {crust }}$ (平均 $3.8 \mathrm{Ga}$ ), 表明形成 该岩体的初始物质十分古老, 至少老于 $2.9 \mathrm{Ga}$, 甚至 可以追溯到冥太古代 (如Ymd7-28 的 $T_{\text {crust }}$ 为 $4.2 \mathrm{Ga}$ ). 这些岩浆结晶锆石和继承锆石均有负的 $\varepsilon_{\mathrm{Hf}}(t) \quad(-26.3$ $\sim-7.3)$, 暗示该岩体的源岩为强烈改造过的地壳物 质. 本地区之前也获得了一些太古宙年龄数据, 如: Zhang等人 ${ }^{[9]}$ 在崆岭杂岩体附近的莲沱组碎屑砂岩中 发现一颗冥太古代碎屑锆石, 该锆石的 U- $\mathrm{Pb}$ 年龄是 $3.8 \mathrm{Ga}, T_{\text {crust }}$ 是 $4.0 \mathrm{Ga}$; Zhang等人 ${ }^{[25]}$ 报道了崆岭杂岩 混合岩和片麻岩 $3.2 \sim 3.5 \mathrm{Ga}$ 的 $T_{\text {crust }}$ 年龄, Qiu等人 ${ }^{[7]}$ 和柳小明等 ${ }^{[26]}$ 也分别获得了 $3.3 \mathrm{Ga}$ 和 $3.3 \sim 3.5 \mathrm{Ga}$ 的 碎屑锆石U-Pb年龄; Zheng等人 ${ }^{[10]}$ 在宜昌附近的京山 煌斑岩捕虏晶中也发现了 $T_{\text {crust }}$ 年龄为 $3.2 \sim 3.5 \mathrm{Ga}$ 的 锆石. 实际上, 崆岭杂岩 TTG片麻岩中 $2.8 \sim 2.9 \mathrm{Ga}$ $\mathrm{U}-\mathrm{Pb}$ 年龄的锆石, 是非常普遍的. 这些事实均表明, 扬子崆岭地区存在太古宙地壳物质, 并且这些太古 宙地壳物质至少老于 $2.9 \mathrm{Ga}$.

(ii ) 古元古代的地壳重熔事件. 圈椅埫花岗岩 (样品Ymd7)锆石 15 个分析结果(表 2)中, 12 个颗粒给 出了近谐和的上交点年龄 $((1853 \pm 12) \mathrm{Ma})$, 与谐和 颗粒的 ${ }^{207} \mathrm{~Pb} /{ }^{206} \mathrm{~Pb}$ 加权平均年龄 $((1854 \pm 17) \mathrm{Ma})$ 一致 (图 4), 可以共同约束该岩体古元古代(1854 Ma)的侵 位结晶事件. 这一结果证实了圈椅埫花岗岩形成于 $\sim 1.85 \mathrm{Ga}$ 的前人认识 ${ }^{[14]}$. 不谐和的Ymd7-25 可能与 $\mathrm{Pb}$ 丢失有关. 谐和颗粒Ymd-28 的U-Pb同位素组成与大 部分古元古代锆石类似(表 2, 图 4), 但Hf同位素组成 却与Ymd7-29 (表 3, 图 5(a), 6(c) (f))和崆岭TTG片 麻岩锆石(图 5(a), 6(c) (f)) 类似, 可能与太古宙锆石 经历古元古代的改造有关，保留了太古宙的Hf同位 素信息和古元古代的U-Pb同位素组成. Ymd7-29 颗粒 的特殊性在于 $\mathrm{Th} / \mathrm{U}$ 比值低 $(0.79),{ }^{207} \mathrm{~Pb} /{ }^{206} \mathrm{~Pb}$ 表面年龄 老((2859 \pm 8$) \mathrm{Ma})$, 表现出与崆岭 TTG片麻岩锆石的 相似性 ${ }^{[7,10,25]}$, 它的 $\left({ }^{176} \mathrm{Hf} /{ }^{177} \mathrm{Hf}\right)_{\mathrm{i}}=0.280749, \varepsilon_{\mathrm{Hf}}(t)=$ $-7.3, T_{\mathrm{DM}}=3.4 \mathrm{Ga}$ 均在崆岭 TTG片麻岩范围内(图 5, 6(a), (b), (e), (f)), 结合其阴极发光图像特征(图 3(f)), 我们的分析点位可能在继承核上, 可能记录着岩浆 侵位结晶过程中继承 TTG 片麻岩锆石的信息. Ymd7-30 颗粒也给出不谐和的年龄, ${ }^{207} \mathrm{~Pb} /{ }^{206} \mathrm{~Pb}$ 表面年 龄高达(3388 14$) \mathrm{Ma}, T_{\mathrm{DM}}$ 值 $(3.0 \mathrm{Ga}$, 而且与其他大多 数颗粒是一致的)低于该表面年龄, 我们目前不好给
出合理的解释, 只是认为可能与继承的锆石受到改 造有关.
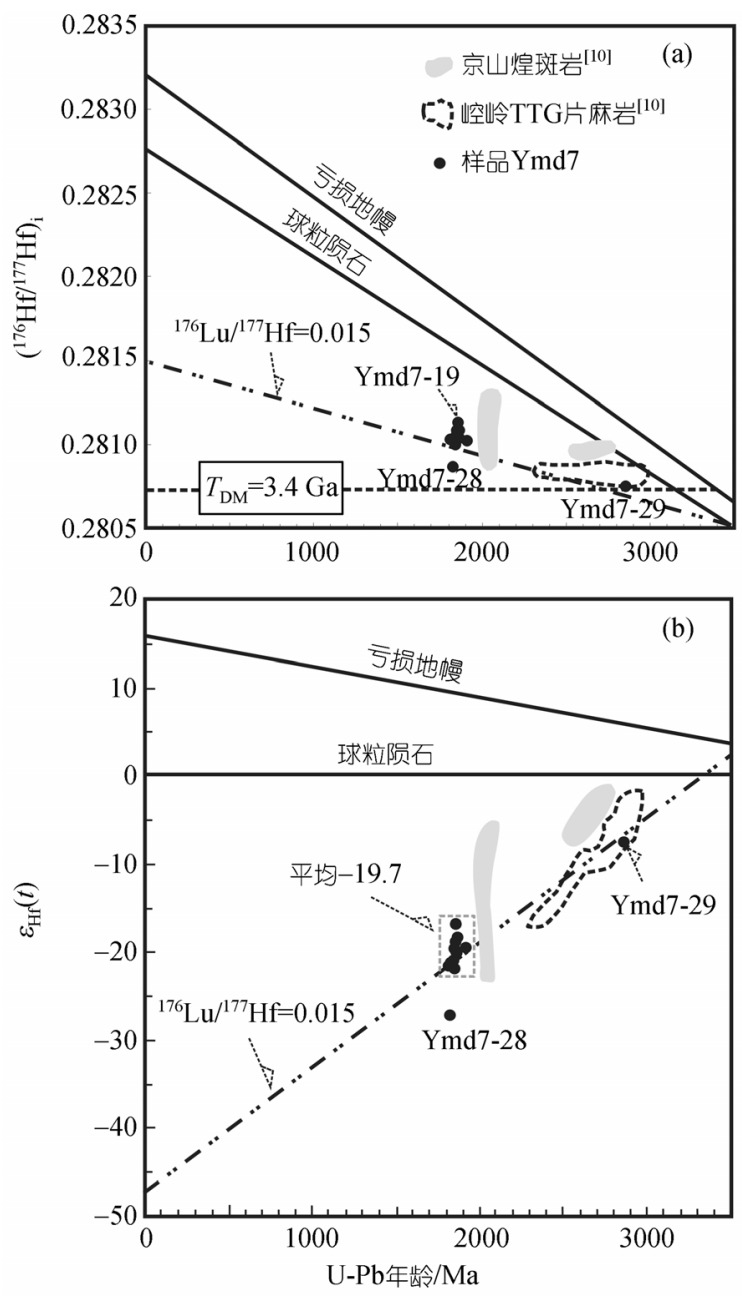

\section{图 5 圈椅埫花岗岩(Ymd7)锆石年龄-Hf 同位素相关图}

我们采用锆石 $\mathrm{U}-\mathrm{Pb}$ 年龄与 $\mathrm{Hf}$ 同位素配套研究的 方法, 来讨论圈椅埫花岗岩的源岩性质. 这种配套研 究已经成为探讨大陆克拉通形成和演化的一种重要 工具, 特别是对经历过多次地质事件的古老岩石, 可 以提供一种理清地质事件序列和示踪源岩性质的可 靠手段 $[9,10,20,25,27 \sim 33]$.

圈椅埫花岗岩锆石 Hf 同位素分析表明: 多数颗 粒的 $\left({ }^{176} \mathrm{Hf} /{ }^{177} \mathrm{Hf}\right)_{\mathrm{i}}$ 和 $\varepsilon_{\mathrm{Hf}}(t)$ 落在 ${ }^{176} \mathrm{Lu} /{ }^{177} \mathrm{Hf}$ 比值为 0.015 的大陆地壳 Hf 同位素演化线上(图 5), 并且崆岭杂岩 TTG 片麻岩也落于该演化线上. 圈椅埫花岗岩源岩 可能为: 1) 崆岭 TTG 片麻岩;2) 来自于比 TTG 岩石 更深的地壳部分. 如果属第一种情况, 那么该岩体锆 

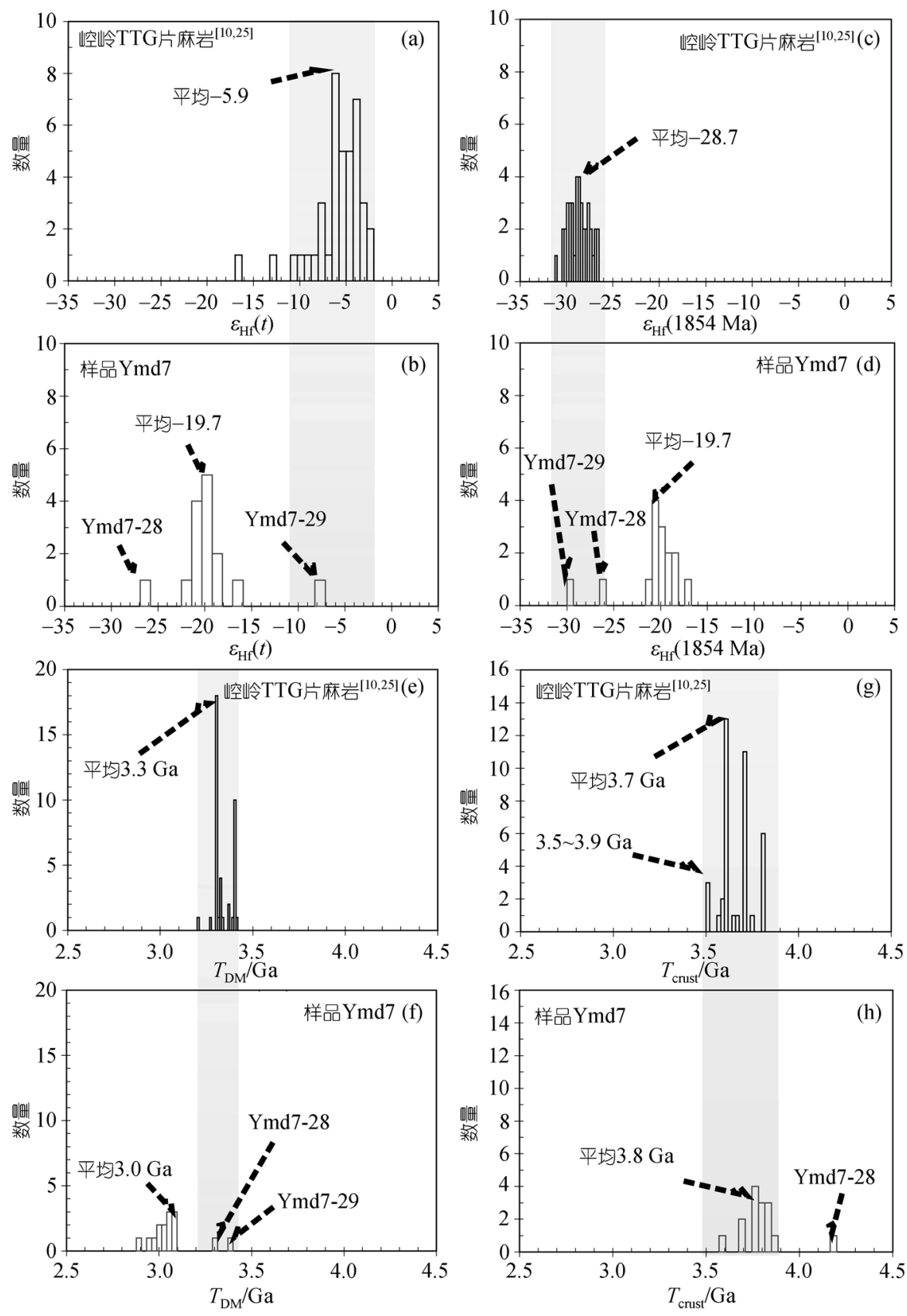

图 6 圈椅埫花岗岩与崆岭 TTG 片麻岩锆石 Hf 同位素组成对比图

图中崆岭 TTG 片麻岩数据来源于文献 $[10,25]$

石会在结晶时记录下 TTG岩石的Hf同位素特征, 即 圈椅埫花岗岩锆石的 $\left({ }^{176} \mathrm{Hf} /{ }^{177} \mathrm{Hf}\right)_{\mathrm{i}} 、 \varepsilon_{\mathrm{Hf}}(t)$ 和 $T_{\mathrm{DM}}$ 值应该 与 TTG片麻岩锆石的 $\left({ }^{176} \mathrm{Hf} /{ }^{177} \mathrm{Hf}\right)_{1854 \mathrm{Ma}}, \varepsilon_{\mathrm{Hf}}(1854 \mathrm{Ma})$ 和 $T_{\mathrm{DM}}$ 值基本一致，但事实上并不是这样(图 5(a), 6(c) (f)). 这些差异说明第一种情况不成立, 即崆岭 TTG片麻岩不是圈椅埫花岗岩的源岩. 实际上二者 之间存在的侵入与被侵入关系, 也说明崆岭 TTG片
麻岩只是圈椅埫花岗岩的围岩. 这样看来, 来自于比 TTG岩石更深的地壳部分作为圈椅埫花岗岩的源岩 可能性更大. 扬子大陆广泛未暴露的太古宙基底 ${ }^{[10]}$ 的存在, 以及扬子崆岭地区太古宙地壳物质的存在, 共同约束圈椅埫花岗岩的源岩极可能为未暴露的太 古宙地壳. 同时, 圈椅埫花岗岩和崆岭 TTG片麻岩具 相似的 $T_{\text {crust }}$ 年龄(图 $6(\mathrm{~g}),(\mathrm{h})$ )范围, 指示它们的初始 
物质具相似性, 都非常古老, 并都存在古太古代组分, 可能都是深部未暴露的太古宙地壳.

\section{2 圈椅埫花岗岩的岩石类型及构造意义}

目前, 对 $\mathrm{A}$ 型花岗岩的确定越来越多地依靠矿物 组成和地球化学判别 ${ }^{[12,13,24,34]}$. Eby ${ }^{[12]}$ 利用主量和微 量元素图解, 将 $\mathrm{A}$ 型花岗岩划分为 $\mathrm{A}_{1}$ 和 $\mathrm{A}_{2}$ 两种构造 环境和源区不同的类型: 其中 $\mathrm{A}_{1}$ 型为非造山的构造 环境(如裂谷带或其它板内环境), 来源于幔源物质; $\mathrm{A}_{2}$ 型可形成于多种构造环境(如碰撞造山带的后造山伸 展环境), 来源于大陆地壳的熔融. 洪大卫等人 ${ }^{[13]}$ 将 $\mathrm{A}$ 型花岗岩划分为非造山和后造山两类, 含义与 $\mathrm{A}_{1}$ 和 $\mathrm{A}_{2}$ 类似.

圈椅埫花岗岩的主量元素和微量元素特征(表 1, 图 2)表明该岩体为 $A$ 型花岗岩. 利用 $R b / N b-Y / N b$ 和 $\mathrm{Nb}-\mathrm{Y}-\mathrm{Ce}$ 判别图解 ${ }^{[12]}$ 对圈椅埫 $\mathrm{A}$ 型花岗岩进行投点 (图 7), 落于 $\mathrm{A}_{2}$ 型的后造山 $\mathrm{A}$ 型花岗岩区域. 其锆石 $\mathrm{U}-\mathrm{Pb}$ 年龄和 $\mathrm{Hf}$ 同位素暗示其源岩为深部太古宙地壳, 并于古元古代 $(\sim 1.85 \mathrm{Ga})$ 发生了熔融作用. 这些事实 表明圈椅埫 $\mathrm{A}$ 型花岗岩是深部太古宙地壳于古元古 代在后造山伸展环境中熔融形成.

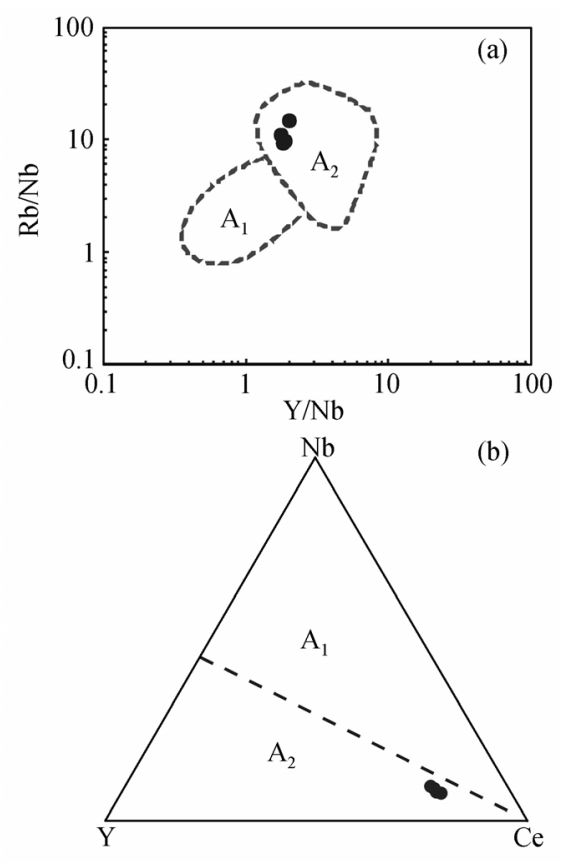

图 7 圈椅埫 $\mathbf{A}$ 型花岗岩 $\mathbf{A}_{1}$ 和 $\mathbf{A}_{2}$ 型判别图解 底图来自文献[12]

4.3 Columbia 超大陆裂解之前的伸展作用在扬子 大陆的响应

Columbia超大陆最早由Hoffman ${ }^{[35]}$ 在总结北美
与格林兰 1.8 2.0 Ga微大陆聚合事件时所提出, 认为 Rodinia超大陆之前曾存在这样的古元古代超大陆. Rogers和 Santosh ${ }^{[36]}$ 将此超大陆命名为 “Columbia”. Zhao等人 ${ }^{[37.38]}$ 汇总了世界典型地区的 $1.8 \sim 2.1 \mathrm{Ga}$ 造 山带的属性, 提出全球大陆在此时期的碰撞聚合事 件, 例如: 南美的Transamazonian造山带 ${ }^{[39]}$, 北美的 Trans-Hudon造山带 ${ }^{[40]}$, 南非的 Limpopo 活动带 ${ }^{[41]}$, 西澳的 Capricorn造山带 ${ }^{[42]}$, 印度中部构造带 ${ }^{[43]}$, 以 及中国华北内部造山带 ${ }^{[44,45]}$ 等. 可见, Columbia超大 陆主要于 $1.8 \sim 2.0 \mathrm{Ga}$ 形成.

此外, 扬子大陆尤其是其北部崆岭杂岩中关于 $1.8 \sim 2.0 \mathrm{Ga}$ 古元古代变质、岩浆热事件, 也有一些报 道. 如凌文黎等 ${ }^{[46]}$ 通过对崆岭杂岩变质岩系的 $\mathrm{Sm}-\mathrm{Nd}$ 定年获得 $1.95 \mathrm{Ga}$ 的变质事件年龄; Qiu等人 ${ }^{[7]}$ 在TTG片麻岩和变泥质岩中分别得到了 1.99 和 1.93 Ga的SHRIMP谐和年龄; Zhang等人 ${ }^{[25,27]}$ 分别获得混 合岩锆石 $2.0 \mathrm{Ga}$ 的变质增生边年龄和变泥质岩、角 闪岩 $1.9 \mathrm{Ga}$ 的变质年龄. 这些都表明崆岭杂岩在 $1.8 \sim$ $2.0 \mathrm{Ga}$ 经历了一系列变质和岩浆热事件, 可能受到了 Columbia超大陆形成的影响.

我们获得圈椅埫 $\mathrm{A}$ 型花岗岩的结晶时间是 (1854 \pm 17$) \mathrm{Ma}$ ，约束了扬子大陆北部古元古代( 1.85 $\mathrm{Ga})$ 的岩浆事件. 此外, 郑永飞和张少兵 ${ }^{[8]}$ 在总结华 南前寒武纪大陆地壳形成和演化时, 汇总了华南大 量的古元古代 $(1.8 \sim 2.0 \mathrm{Ga})$ 岩浆和变质事件, 指出可 能与Columbia超大陆的形成有关; Zhang等人 ${ }^{[27]}$ 也在 总结了扬子大陆广泛的古元古代(1.8 $2.0 \mathrm{Ga})$ 岩浆 和变质事件基础上, 提出这些事件可能与扬子大陆 古元古代克拉通化过程有关. 由此可见, 扬子大陆可 能在Columbia超大陆形成的影响下, 于古元古代发 生了克拉通化作用, 圈椅埫 $\mathrm{A}$ 型花岗岩的形成记录着 该克拉通化作用的晚期过程.

Zhang等人 ${ }^{[47]}$ 在分析崆岭杂岩附近的新元古代 晓峰岩墙成因时, 用深部太古宙地壳的熔融作用来 解释, 并且与超大陆聚合后的岩石圈伸展作用引起 的地壳拉张垮塌有关. 这一思路可能也适用于古元 古代的情况. 因此, 我们解释圈椅埫 $\mathrm{A}$ 型花岗岩, 是 在Columbia超大陆聚合之后-裂解之前的期间, 扬子 北部形成的碰撞造山带在大陆岩石圈的伸展作用下， 引起深部太古宙地壳在后造山的伸展环境中发生拉 张垮塌, 所熔融产生的花岗岩. 


\section{5 主要认识}

侵位于湖北宜昌崆岭杂岩中的圈椅埫花岗岩为 后造山的 $\mathrm{A}$ 型花岗岩. 岩体结晶年龄为 (1854 \pm 17$)$ Ma. 这些锆石有非常低的 $\varepsilon_{\mathrm{Hf}}(t)(-26.3 \sim-16.7)$ 和古老的亏 损地幔模式年龄 $\left(T_{\mathrm{DM}}=2.9 \sim 3.3 \mathrm{Ga}\right.$, 平均 $\left.3.0 \mathrm{Ga}\right)$ 及平 均地壳模式年龄 $\left(T_{\text {crust }}=3.6 \sim 4.2 \mathrm{Ga}\right.$, 平均 $\left.3.8 \mathrm{Ga}\right)$; 表面年龄为 $2859 \mathrm{Ma}$ 的锆石继承核给出略高的 $T_{\mathrm{DM}}$
(3.4 Ga)以及与这些古元古代锆石相似的 $T_{\text {crust }}(3.8$ $\mathrm{Ga})$. 说明该岩体的源岩可能来自扬子大陆深部太古 宙地壳, 其初始物质非常古老, 至少老于 $2.9 \mathrm{Ga}$. 这 样的物质于古元古代在后造山伸展环境中发生熔融 形成花岗岩. 这一熔融事件记录着扬子大陆古元古 代克拉通化过程, 可能在 Columbia 超大陆聚合后-裂 解前的期间, 与大陆岩石圈的伸展作用所引起的深 部太古宙地壳拉张垮塌产生熔融作用有关.

感谢澳大利亚 Macquarie 大学 O'Reilly 和 Griffin 教授的样品测试安排. 感谢中国地质大学(武汉)吴元保教授提 供了部分全岩分析样品(06HL01 和 06HL02)以及评审人对本文提出的宝贵意见.

\section{参考文献}

1 Jahn B M, Auvray B, Cornichet J, et al. 3.5 Ga old amphibolites from eastern Hebei Province, China: Field occurrence, petrography, Sm-Nd isochron age and REE geochemistry. Precambrian Res, 1987, 34: 311-346[DOI]

2 Jahn B M, Ernst W G. Late Archean Sm-Nd isochron age for mafic-ultramafic supracrustal amphibolites from the Northeastern Sino-Korean Craton, China. Precambrian Res, 1990, 46: 295-306[DOI]

3 Liu D Y, Nutman A P, Compston W, et al. Remnants of $>$ or $=3800$ Ma crust in the Chinese part of the Sino-Korean craton. Geology, 1992, 20: 339-342[DOI]

4 Song B, Nutman A P, Liu D Y, et al. 3800 to 2500 Ma crustal evolution in the Anshan area of Liaoning Province, northeastern China. Precambrian Res, 1996, 78: 79-94[DOI]

5 Zheng J P, Griffin W L, O’Reilly S Y, et al. 3.6 Ga lower crust in central China: New evidence on the assembly of the North China craton. Geology, 2004, 32: 229-232[DOI]

6 Gao S, Ling W L, Qiu Y M, et al. Contrasting geochemical and Sm-Nd isotopic compositions of Archean metasediments from the Kongling high-grade terrain of the Yangtze craton: Evidence for cratonic evolution and redistribution of REE during crustal anatexis. Geochim Cosmochim Acta, 1999, 63: 2071-2088 $\underline{\text { [DOI] }}$

7 Qiu Y M, Gao S, McNaughton N J, et al. First evidence of $>3.2 \mathrm{Ga}$ continental crust in the Yangtze craton of south China and its implications for Archean crustal evolution and Phanerozoic tectonics. Geology, 2000, 28: 11-14[DOI] 郑永飞, 张少兵. 华南前寒武纪大陆地壳的形成和演化. 科学通报, 2007, 52(1): 1-10

9 Zhang S B, Zheng Y F, Wu Y B, et al. Zircon U-Pb age and Hf isotope evidence for $3.8 \mathrm{Ga}$ crustal remnant and episodic reworking of Archean crust in South China. Earth Planet Sci Lett, 2006, 252: 56-71표

Zheng J P, Griffin W L, O’ Reilly S Y, et al. Widespread Archean basement beneath the Yangtze craton. Geology, 2006, 34: 417$420 \underline{\text { [DOI] }}$

11 Loiselle M C, Wones D R. Characteristics and origin of anorogenic granites. Geol Soc Am Abstr Prog, 1979, 11: 468

12 Eby G N. Chemical subdivision of the A-type granitoids: Petrogenetic and tectonic implications. Geology, 1992, 20: 641-644[DOI]

13 洪大卫，王式洸，韩宝福，等。碱性花岗岩的构造环境分类及其鉴别标识. 中国科学 B 辑, 1995, 25(4): 418-426

14 袁海华，张志兰，刘炜，等. 直接测定颗粒锆石 ${ }^{207} \mathrm{~Pb} /{ }^{206} \mathrm{~Pb}$ 年龄的方法. 岩石矿物, 1991, 11(2): 72-79

15 马国干, 李华芹, 张自超。华南地区震旦纪时限范围的研究. 宜昌地质矿产研究所所刊, 1984, 8: 1-29

16 胡圣虹, 陈爱芳, 林守麟, 等. 地质样品中 40 个微量、痕量、超痕量元素的 ICP-MS 分析研究. 地球科学, 2000, 25(2): 186190

17 Andersen T. Correction of common lead in U-Pb analyses that do not report ${ }^{204} \mathrm{~Pb}$. Chem Geol, 2002, 192: 59-79 [DOI]

18 Belousova E A, Griffin W L, O'Reilly S Y, et al. Igneous zircon: Trace element composition as an indicator of source rock type. Contrib Miner Petrol, 2002, 143: 602-622

19 Jackson S E, Pearson N J, Griffin W L, et al. The application of laser ablation-inductively coupled plasma-mass spectrometry to in situ U-Pb zircon geochronology. Chem Geol, 2004, 211: 47-69[DOI]

20 Griffin W L, Pearson N J, Belousova E, et al. The Hf isotope composition of cartonic mantle: LAM-MC-ICPMS analysis of zircon megacrysts in kimberlites. Geochim Cosmochim Acta, 2000, 64: 133-147표 
21 Blichert-Toft J, Albarede F. The Lu-Hf geochemistry of chondrites and the evolution of the mantle-crust system. Earth Planet Sci Lett, 1997, 148: 243-258[DOI]

Scherer E, Munker C, Mezger K. Calibration of the Lutetium-Hafnium clock. Science, 2001, 293: 683-687 [DOI]

Griffin W L, Wang X, Jackson S E, et al. Zircon chemistry and magma mixing, SE China: In-situ analysis of the Hf isotopes, Tonglu and Pingtan igneous complexes. Lithos, 2002, 61: 237-269[DOI]

Whalen J B, Currie K L, Chappell B W. A-type granites: Geochemical characteristics, discrimination and petrogenesis. Contrib Miner Petrol, 1987, 95: 407-419 [DOI]

Zhang S B, Zheng Y F, Wu Y B, et al. Zircon isotope evidence for $\geqslant 3.5$ Ga continental crust in the Yangtze craton of China. Precambrian Res, 2006, 146: 16-34[DOI]

柳小明, 高山, 凌文黎, 等. 扬子克拉通 35 亿年碎屑锆石的发现及其地质意义. 自然科学进展, 2005, 15(11): 1334一1337

Zhang S B, Zheng Y F, Wu Y B, et al. Zircon U-Pb age and Hf-O isotope evidence for Paleoproterozoic metamorphic event in South China. Precambrian Res, 2006, 151: 265-288[DOI]

Stevenson R K, Patchett P J. Implications for the evolution of continental-crust from Hf-isotope systematics of Archean detrital zircons. Geochim Cosmochim Acta, 1990, 54: 1683-1697[DOD]

Amelin Y, Lee D C, Halliday A N, et al. Nature of the Earth's earliest crust from hafnium isotopes in single detrital zircons. Nature, 1999, 399: 252-255[DOI]

Amelin Y, Lee D C, Halliday A N, et al. Early-middle Archaean crustal evolution deduced from Lu-Hf and U-Pb isotopic studies of single zircon grains. Geochim Cosmochim Acta, 2000, 64: 4205-4225[DOI]

Griffin W L, Belousova E A, Shee S R, et al. Archean crustal evolution in the northern Yilgan Craton: U-Pb and Hf-isotope evidence from detrital zircons. Precambrian Res, 2004, 131: 231-282 [DOI]

Zheng J P, Griffin W L, O'Reilly S Y, et al. Zircons in mantle xenoliths record the Triassic Yangtze-North China continental collision. Earth Planet Sci Lett, 2006, 247: 130-142[DOI]

吴福元，李献华，郑永飞，等. Lu-Hf 同位素体系及其岩石学应用. 岩石学报, 2007, 23(2): 185-220

Wu F Y, Sun D Y, Li H M, et al. A-type granites in northeastern China: Age and geochemical constraints on their petrogenesis. Chem Geol, 2002, 187: 143-173 [DOI]

Hoffman F P. Speculations on Laurentia’s first gigayear (2.0 to $1.0 \mathrm{Ga}$ ). Geology, 1989, 17: 135-138 [DOI]

Rogers J J W, Santosh M. Configuration of Columbia, a Mesoproterozoic supercontinent. Gondwana Res, 2002, 5: 5-22[DOI]

Zhao G C, Cawood P A, Wilde S A, et al. Review of global 2.1-1.8 Ga orogens: Implications for a pre-Rodinia supercontinent. Earth Sci Rev, 2002, 59: 125-162[DOI]

Zhao G C, Sun M, Wilde S A, et al. A Paleo-Mesoproterozoic supercontinent: Assembly, growth and breakup. Earth Sci Rev, 2004, 67: $91-123[\underline{\mathrm{DOI}]}$

Alkmim F F, Marshak S. Transamazonian Orogeny in the Southern São Francisco Craton Region, Minas Gerais, Brazil: Evidence for Paleoproterozoic collision and collapse in the Quadrilátero Ferrífero. Precambrian Res, 1998, 90: 29-58 [DOI]

Hoffman F P. United plates of America, the birth of a craton. Annu Rev Earth Planet Sci, 1988, 16: 543-603 [DOI]

Holzer L, Frei R, Baeton J M, et al. Unraveling the record of successive high-grade events in the Central Zone of the Limpopo Belt using $\mathrm{Pb}$ single phase dating of metamorphic minerals. Precambrian Res, 1998, 87: 87-115[이]

Van Kranendonk M J, Collins W J. Timing and tectonic significance of Late Archean, sinistral strike-slip deformation in the Central Pilbara Structural Corridor, Pilbara Craton, Western Australia. Precambrian Res, 1998, 88: 207-232[DOI]

Mazumder R, Bose P K, Sarkar S. A commentary on the tectono-sedimentary record of the pre-2.0 Ga continental growth of India vis-a-vis a possible pre-Gondwana Afro-Indian supercontinent. J Asian Earth Sci, 2000, 30: 201-217

Zhao G C, Cawood P A, Wilde S A, et al. Metamorphism of basement rocks in the Central Zone of the North China Craton: Implications for Paleoproterozoic tectonic evolution. Precambrian Res, 2000, 103: 55-88[DOI]

Zhao G C, Sun M, Wilde S A, et al. Late Archean to Paleoproterozoic evolution of the North China Craton: Key issues revisited. Precambrian Res, 2005, 136: 177-202[DOI]

凌文黎, 高山, 张本仁, 等. 扬子陆核古元古代晚期构造热事件与扬子克拉通演化. 科学通报, 2000, 45(21): 2343-2348

Zhang S B, Zheng Y F, Zhao Z F, et al. Neoproterozoic anatexis of Archean lithosphere: Geochemical evidence from felsic to mafic intrusions at Xiaofeng in the Yangtze Gorge, South China. Precambrian Res, 2008, 163: 210-238[DOI] 